draws attention to the need for developing bioethics education on all levels in the countries in transition; efforts to improve the level of knowledge have been made in Lithuania, Estonia, Latvia, Poland, Slovenia, Czech Republic, Slovak Republic, Hungary, Romania, Bulgaria, and Croatia. ${ }^{3}$

Another trait is a strong paternalistic tendency, especially among older healthcare staff who have a more traditional view on the doctor-patient relationship and medical ethics. ${ }^{6}$ This is reflected in the work of ethics committees, which are often made up of older doctors, as in the Croatian case-probably because the experience of older doctors is equated with their competence in medical ethics. Here we find a traditional approach to medical ethics: older, more experienced doctors are thought to be competent enough to converse about ethical issues just because they have considerable experience to draw their knowledge from.

\section{Conclusions}

The work of ethics committees in Croatia can be viewed as one of satisfying norms and requirements within a healthcare system. However, healthcare systems are also about people and relationships, and when that is ignored it can create a lot of strain on both providers and users, creating unresolved issues and tensions as well as ethical problems. Healthcare organisations should be based on webs of relationships and interactions between people, promoting ethical values, trying to foster patients' best interests, and having responsibilities.

We thank Darko Hren for help with statistical analysis and the National Bioethics Committee for Medicine of the Government of the Republic of Croatia for permission to use its data and help with sending out the questionnaires.

\section{Summary points}

In European countries in transition, like Croatia, the healthcare system has a bureaucratic climate and approach

Ethics committees in such a climate are bureaucratically constituted entities whose functions consist mainly of analysing research protocols

Members of hospital ethics committees have insufficient knowledge of ethical issues and a paternalistic approach

Ignoring people and relationships can strain both providers and users, creating unresolved issues and tensions and ethical problems.

Contributors: $\mathrm{AB}$ planned and conducted the study, composed the questionnaire, collected and analysed data, and prepared the manuscript. HtH and SO planned the study and revised the questionnaire. $\mathrm{AB}, \mathrm{HtH}$, and $\mathrm{SO}$ prepared the manuscript. $\mathrm{AB}$ is guarantor.

Competing interests: None declared.

1 Emanuel LL. Ethics and the structures of healthcare. HEC Forum 2000;9:151-68.

McKee M, Fister K. Post-communist transition and health in Europe. BMJ 2004;329:1355-6.

3 Gefenas E. Is "failure to thrive" syndrome relevant to Lithuanian healthcare ethics committees? HEC Forum 2001;13:381-92.

4 Siegler M. Ethics committees: decisions by bureaucracy. Hastings Centre Siegler M. Ethics con
Report 1986;16:22-4.

Report 1986;16:22-4.
Borovečki A, ten Have H, Orešković S. Ethical issues in medicine in the Republic of Croatia. Cambridge Quarterly of Healthcare Ethics 2004:3;263-6.

6 Javashvili G, Kiknadze G. Ethics committes in Georgia. In: Glasa J, ed. Ethics committees in central and eastern Europe. Bratislava: Charis IEMB, 2000:179-185.

7 Oreskovic S. New priorities for health sector reform in central and eastern Europe. Croat Med J 1998;3:225-33.

8 Glasa J. Bioethics and the challenges of a society in transition: the birth and development of bioethics in post-totalitarian Slovakia. Kennedy Institute of Ethics Journal 2000;2:165-70.

9 Drane JF. Basic facts about health care ethics committees. In: Clinical Drane JF. Basic facts about health care ethics com
bioethics. Kansas City: Sheed and Ward, 1994:1-16.

10 Van der Kloot HH, ter Meulen RHJ. Developing standards for institutional ethics committees: lessons from the Netherlands.J Med Ethics 2001;27(suppl):i36-40.

\title{
Commentary: Ethics committees and countries in transition: a figleaf for structural violence?
}

\author{
Richard E Ashcroft
}

Borovečki and colleagues argue that hospitals are ethical institutions, and that the norms they embody are subject to pressure and change as the institutions and their contexts change. ${ }^{1}$ They discuss how bioethics as an explicit way of discussing ethical norms and moral dilemmas has increasingly been institutionalised within Croatian hospitals, and analyse some of the defects of this process to date. In particular they identify three main features of hospital ethics committees which undermine their effectiveness: a continuing tradition of paternalism within medical practice; the bureaucratic, top-down implementation of ethics committees within the Croatian healthcare system; and the confusion of roles between hospital ethics committees and research ethics committees.

Some of their findings bear further analysis: for instance, it is not clear what is "average" in terms of the ethical knowledge of ethics committee members, either in absolute terms (what is the ideal for what they ought to know?) or in relative terms (average compared with whom?). These issues remain open questions in most of the countries in which ethics committees and ethics consultation have been implemented for much longer. $^{23}$ Yet the issues presented in this article resonate across European health systems, despite considerable variation in the implementation of and rationale for ethical decisions in clinical practice.

Given the nature of health systems reform and socioeconomic transition in eastern Europe, what problems is clinical ethics supposed to address, and why should it be a solution to them? Many health systems in Europe are under considerable strain: problems of inadequate resources, high direct costs for patients, inequalities in access, corruption, and formal or informal rationing are as real as the "traditional" clinical ethics issues concerning decision making at the end of life or resolution of conflicts between family members and staff. In addition, as clinical research
Imperial College London, London W6 8RP Richard E Ashcroft reader

r.ashcroft@ imperial.ac.uk 
increasingly migrates to health systems, imposing lower costs on sponsors or researchers, hospitals have strong incentives to take on research projects that may not be in the best interests of the patients or the institution as a whole. Yet it is far from clear that the resources of clinical ethics are particularly apt for addressing these kinds of problems of structural adjustment or professional "deformation." ${ }^{4}$ The language of ethics risks being used to ratify decisions made for reasons of pragmatism or expediency. Institutions may find it more useful to set up ethics committees more to satisfy foreign partners' or research sponsors' requirements, rather than to address problems of concern to patients.

Ethics committees can serve many useful functions: education, dispute resolution, regulation, policy development. To be genuinely useful to clinicians and patients, and to be morally legitimate, ethics committees need to have both a clear sense of purpose and a clear sense of how best to achieve that purpose. Medical ethics scholars must take up the challenge of addressing the moral problems of social transition, otherwise they will be merely a moral figleaf covering the structural violence in countries in transition. ${ }^{5}$

Competing interests: None declared.

1 Borovečki A, ten Have H, Orešković S. Ethics and the structures of health care in the European countries in transition: hospital ethics committees in Croatia. BMJ 2005:331:227-9.

2 Slowther A, Johnstone C, Goodall J, Hope T. Development of clinical ethics committees. BMJ 2004;328:950-2.

3 Royal College of Physicians. Ethics in practice. London: Royal College of Physicians, 2005 .

Physicians, 2005.
Dwyer J. Teaching global bioethics. Bioethics 2003;17:432-46.

5 Farmer P. Pathologies of power: health, human rights, and the new war on the poor. Berkeley: University of California Press, 2005.

\section{Commentary: Ethics in health care and research in European transition countries: reality and future prospects}

Ana Marušić

Croatian Medical Journal, Šalata 3, HR-10000 Zagreb, Croatia

Ana Marušić editor

marusica@mef.hr
Borovečki et al examined the structure and performance of hospital ethics committees in Croatia, as a paradigm of healthcare ethical regulations in transitional countries. ${ }^{1}$ They found out that these bodies were highly bureaucratic and concerned almost exclusively with approval of research protocols, and that their members were mostly older physicians without the knowledge and skills that would be useful for the other functions of the ethics committees (education, guidelines development and ethical case analysis).

The same legalistic and bureaucratic organisation is a characteristic of the whole legal regulation of health care and health professionals in a transitional country such as Croatia. ${ }^{2}$ It is thus not surprising that ethical regulations are taken lightly and that their breach is common. For example, cheating, as an example of unethical behaviour, is very common among medical students in Croatia. ${ }^{3}$ A study of attitudes towards cheating, involving economics students in Russia, Israel, the Netherlands, and the United States, showed good correspondence between students' perception of cheating and corruption in the society. ${ }^{4}$ In contrast with the United States and many Western countries, where cheating is considered unfair competition and is condemned, in former communist countries the governmental system was always a servant of the party and thus considered an enemy by most citizens. High cheating rates among students and their permissiveness towards cheating, as well as a lax approach to ethical norms in general, can be explained by socioeconomic laws: the less consistently a norm is observed in a society, the lower the cost incurred by an individual deviating from the norm. ${ }^{4}$ The universities and healthcare institutions alike have a set of norms which are similar to those in most developed democracies, but they are usually buried in the legal departments (and now in the intranet pages) of the schools and institutions, and there is little education or institutional enforcement of adherence to the norms. Even analysis into the system and quality assessment is often not welcome: when we published the results of our study on academic misbehaviour of medical students, ${ }^{3}$ some of our colleagues regarded it as "not a nice thing to say about our school."

So what can be done? Realistically, bureaucratic and dishonest behaviour cannot be completely eliminated before other sectors of the society improve. For countries joining the European Union, any change must come from within, as the countries that made up the "old" EU may not provide the best example. Bureaucratisation, the closed nature of academia, and self sustenance of academic communities are not restricted to small scientific communities in former communist countries. Favouritism or "inbreeding" at universities, defined as the percentage of teachers at a university who trained at the same university, is especially high in Portugal (91\%), Spain (88\%), Italy $(78 \%)$, Austria $(73 \%)$, and France $(56 \%)$, compared with the UK (5\%) and Germany $(1 \%){ }^{5}$ What the EU can do for its new members or in negotiations with future members is to insist not only on high ethical standards in medicine but also on their implementation. Only education and transparent regulatory actions can improve the integrity of both present and future doctors and promote responsible and trustworthy physicians as leaders of changes in society.

Competing interests: None declared.

1 Borovečki A, ten Have H, Orešković S. Ethics and the structures of health care in the European countries in transition: hospital ethics committee in Croatia. BMJ 2005;331:227-9.

2 Bošnjak D, Marušić A. Croatia: legal regulation of doctors. Lancet 2000; 356:1349-50.

Hrabak M, Vujaklija A, Vodopivec I, Hren D, Marušić M, Marušić A Academic misconduct among medical students in a transition country. Med Educ 2004,38:276-85

4 Magnus JR, Polterovich VM, Danilov DL, Savvateev AV. Tolerance to cheating: an analysis across countries. J Econom Educ 2002;33:125-35.

5 Soler M. How inbreeding affects productivity in Europe. Nature 2001;411:132. 